\title{
Plasma ghrelin levels in children with cystic fibrosis and healthy children
}

\author{
Maryam Monajemzadeh', Shahrzad Mokhtari', Farzaneh Motamed², Sedigheh Shams', \\ Mohammad Taghi Haghi Ashtiani ${ }^{1}$, Ata Abbasi ${ }^{1}$, Mehri Najafi Sani², Ehsan Sadrian ${ }^{1}$
}

\begin{abstract}
1Department of Pathology, Children's Medical Center Hospital, Tehran University of Medical Sciences, Keshavarz Boulevard, Tehran, Iran

2Department of Pediatric Gastroenterology, Children's Medical Center Hospital, Tehran University of Medical Sciences, Keshavarz Boulevard, Tehran, Iran
\end{abstract}

Submitted: 30 January 2011

Accepted: 21 April 2011

Arch Med Sci 2013; 9, 1: 93-97

DOI: 10.5114/aoms.2012.28599

Copyright $\odot 2013$ Termedia \& Banach

\section{Abstract}

Introduction: Cystic fibrosis (CF) is a common genetic disorder as a result of mutation in the CF transmembrane conductance regulator gene. Weight loss in CF patients seems to be multifactorial and metabolic factors, inflammation, recurrent infections and poor appetite are possible candidates. Ghrelin affects energy hemostasis by stimulating growth hormone secretion, glucose and lipid metabolism alteration and inhibition of the inflammatory system. Data on the role of ghrelin in energy deficiency in CF patients are sparse and controversial. The study was done to compare the plasma levels of the acylated form of ghrelin in CF patients with healthy participants.

Material and methods: Thirty cystic fibrosis patients (aged 1-168 months) and thirty healthy matched participants were enrolled in the study. Plasma ghrelin and albumin levels were measured and body mass index (BMI) was calculated as well.

Results: Plasma levels of acylated ghrelin in CF patients were significantly higher than the control group (mean $25-75 \%$ : 14.5 vs. $2.7, p=0.032$ ). Body mass index measurements in CF patients were significantly lower than the control group $(p<0.001)$. Using regression analysis there was no statistically significant correlation between plasma ghrelin levels and serum albumin, weight, height or BMI values in CF patients and controls.

Conclusions: The acylated ghrelin levels are increased in CF. So plasma levels of acylated ghrelin could be used as an indicator of food uptake and energy balance in them. Further studies should be established to find out the exact role of factors affecting energy metabolism.

Key words: ghrelin, children, cystic fibrosis, body mass index.

\section{Introduction}

Cystic fibrosis (CF) is a common genetic disorder of ion transport in epithelial cells as a result of mutation in the CF transmembrane conductance regulator gene which affects chloride channel function and fluid secretion in organs, especially the respiratory system and gastrointestinal tract (Gl). The disease is characterized by chronic energy deficiency resulting in poor survival of patients [1]. Body weight and fat are two factors that positively affect CF patients' survival, and decreased body mass index (BMI) worsens lung function and is an independent risk factor for mortality in CF [2].

\section{Corresponding author:}

Maryam Monajemzadeh MD

Pathology Department

Children's Medical

Center Hospital

Tehran University

of Medical Sciences

Keshavarz Boulevard

Tehran, Iran

Phone: +98 2166922115

E-mail: monajemz@tums.ac.ir 
Weight loss in CF patients seems to be multifactorial and the exact cause is still obscure. However, metabolic factors, increased inflammation, recurrent infections and poor appetite are possible candidates. The interactions between peptide hormones affect appetite and food uptake and increase in inflammatory system activation and cytokine levels such as IL1, IL6 and TNF - are mentioned to be involved in the wasting process in CF [3].

Ghrelin, a hormone secreted by enteroendocrine cells of the gastric mucosa, was discovered in 1999 by Kojima et al. [3] and is mentioned as an important factor in appetite stimulation and energy hemostasis. Ghrelin affects energy hemostasis by stimulating growth hormone $(\mathrm{GH})$ secretion, glucose and lipid metabolism alteration and inhibition of the inflammatory system [4-9].

Ghrelin is generated from a precursor called pre-pro ghrelin and during post-translational modifications, the acylated form is produced (octanoylated ghrelin). This acylation is necessary for the peptide to be able to bind to its receptor called GH-R1 to exert its biological effects [10-13]. According to the literature, although the dominant form of ghrelin peptide in plasma is the unacylated ghrelin, its biological activities depend on the peptide acylation [7]. Data on the role of ghrelin in energy deficiency in CF patients are scarce and controversial. Cohen et al., in a study in CF subjects, measured lymphocytic ghrelin receptor expression and BMI [14] and in another study on adult CF cases, they measured ghrelin levels [2].

Nevertheless, the existing data are mostly on the association of the unacylated form of ghrelin and CF energy wasting, while the role of the acylated form of the peptide is not mentioned. In addition, there is only limited research about this hormone and CF, and to our knowledge there are no published data concerning young children yet. To further investigate the role of ghrelin in children with cystic fibrosis related wasting, we studied cystic fibrosis patients in the Children's Medical Center Hospital, the major children's hospital of Iran, which is a tertiary university hospital admitting many patients from all parts of Iran. The scope of this research is to compare the plasma levels of the acylated form of ghrelin in CF patients with healthy participants and explore probable differences between plasma levels of this peptide and albumin, BMI markers and stool fat in two groups.

\section{Material and methods}

\section{Patients}

Between May 2008 and May 2010, thirty cystic fibrosis patients (14 male and 16 female, mean age: $45.3 \pm 8.26$ months, range 1 to 168 months) and thirty healthy participants matched for age and sex (15 male and 15 female, mean age $54.5 \pm 8.6$ months, range 8 to 180 months) were enrolled in this case- control study. Written informed consent was obtained from their families.

The patients were diagnosed using high sweat chloride concentration (greater than $60 \mathrm{mEq} / \mathrm{l}$ ) on two samples and in a few (6 cases) confirmed by genetic analysis (PCR). All the patients were clinically stable and had no evidence of pulmonary exacerbation such as cough or dyspnea. All patients with pancreatic insufficiency were treated with enzyme replacement therapy and had no clinical signs or symptoms such as pancreatitis. Screening was done for all participants by medical history and physical examination. Body weight and height were measured and BMI $\left(\mathrm{kg} / \mathrm{m}^{2}\right)$ was then calculated [15]. Blood sampling from all the participants was performed after overnight fasting in older children in tubes containing EDTA and $p$-hydroxymercuribenzoic acid to prevent degradation of acylated ghrelin. Samples were then centrifuged twice at $+4^{\circ} \mathrm{C}$ with addition of $\mathrm{HCl}$. The supernatants were stored at $-20^{\circ} \mathrm{C}$ until assayed according to the manufacturer's guidelines (human acylated ghrelin ELISA kit, Biovendor, Czech Republic).

\section{Ghrelin assessment}

Serum ghrelin level was measured using a commercial enzyme immunometric assay (human acylated ghrelin ELISA kit, Biovendor, Czech Republic) [16]. The assay was based on a double-antibody sandwich technique. The antibody within the kit has no cross-reaction with any other relevant proteins within the samples according to the manufacturer. The kit contained 8 standards with different concentrations. In order to confirm the results and assess their precision, 10 of the samples were measured twice and the duplicated data were compared with the initial ones.

Fecal fat measurement was also performed using Sudan staining [17] and the serum albumin levels were measured using a Hitachi autoanalyser (Hitachi 717 autoanalyser, Tokyo, Japan).

\section{Statistical analysis}

The results are expressed as mean \pm SEM. Data were tested for normality using the KolmogorovSmirnov test using $p=0.05$ as the threshold for rejection of normality. Statistical analysis was performed using SPSS version 16.0.1 (SPSS Inc., Chicago, IL, U.S.A.). The statistical differences between proportions were determined by $\chi^{2}$ analysis; the statistical significance of differences between means was determined by Mann-Whitney $U$ analysis for nonparametric and independent Student's $t$-test analysis for normal values. The correlation between numerical data was analyzed using linear regression. Value of $p<0.05$ was considered as significant.

The authors had no conflict of interest. The study protocol was approved by the Department Research 
Table I. Anthropometric characteristics in CF (cystic fibrosis) patients and healthy control (NL) group $($ mean \pm SEM)

\begin{tabular}{|lccc|}
\hline Parameter & $\begin{array}{c}\text { CF } \\
(n=30)\end{array}$ & $\begin{array}{c}\text { NL } \\
(n=30)\end{array}$ & Value of $p$ \\
\hline Weight $[\mathrm{kg}]$ & $15.7 \pm 2.6$ & $20.7 \pm 2.07$ & 0.03 \\
\hline $\mathrm{BMI}\left[\mathrm{kg} / \mathrm{m}^{2}\right]$ & $19.5 \pm 4.2$ & $20.34 \pm 0.65$ & $<0.001$ \\
\hline $\begin{array}{l}\text { Albumin } \\
{[\mathrm{mg} / \mathrm{dl}]}\end{array}$ & $4.4 \pm 1.1$ & $4.8 \pm 0.08$ & 0.008 \\
\hline $\begin{array}{l}\text { Age } \\
{[\text { months }]}\end{array}$ & $49.4 \pm 8.2$ & $54.5 \pm 8.6$ & $\begin{array}{c}\text { Not statically } \\
\text { significant }\end{array}$ \\
\hline Male & 14 & 19 & $\begin{array}{c}\text { Not statically } \\
\text { significant }\end{array}$ \\
\hline Female & 16 & 11 & $\begin{array}{c}\text { Not statically } \\
\text { significant }\end{array}$ \\
\hline
\end{tabular}

Committee of Tehran University of Medical Sciences and written informed consent was obtained from all participants prior to blood tests.

\section{Results}

The characteristic data of the two groups are shown in Table I. There was no statistically significant difference between the two groups in age or gender distribution. Plasma levels of acylated ghrelin in CF patients were significantly higher than the control group (mean 25-75\%: 14.5 vs. 2.7, $p=0.032$ ), Figure 1. Body mass index values in CF patients were statistically significantly lower than the control group ( $p<0.001)$; also the prevalence of being underweight $\left(\mathrm{BMl}<20 \mathrm{~kg} / \mathrm{m}^{2}\right)$ in patients was higher than in controls $(p=0.006)$. The mean body weight in the control group was higher than CF patients and the difference was statistically significant $(p=0.03)$. The albumin plasma level in CF patients was lower than the control group $(p=0.008)$ but there was no statistically significant difference between the two groups in fecal fat. There was no statistically significant difference between males and females in BMI, albumin or ghrelin levels within groups. According to regression analysis there was no statistical significant correlation between plasma ghrelin levels and serum albumin, weight, height or BMI values in CF patients or the control group.

\section{Discussion}

The CF is the most common life-threatening autosomal recessive disease in whites and it is estimated to have an incidence of 1 in 3,200 live births in the United States [18]. The predominant clinical manifestations are variable and the course of the disease ranges from early onset of pulmonary complications leading to death to mild disease appearing later in life. The main predictors of mortality

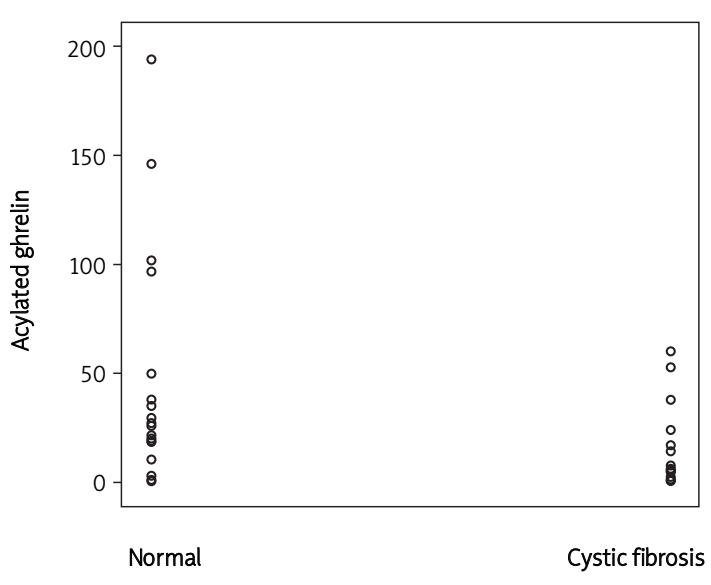

Figure 1. Distribution of median plasma levels of acylated ghrelin in 30 patients with cystic fibrosis (CF) and 30 healthy controls (NL)

are pulmonary state, airway microbiology, and nutritional factors. Survival has improved nowadays by means of current supportive modulations in many of those affected so we can observe older patients recently and the age of death is higher than the past, and chronic complications such as wasting can be more pronounced in them [19]. There are many factors affecting energy balance in our body, e.g. hormones, the inflammatory system and various cytokines; some have a positive and some a negative effect on energy balance. Among these, it is mentioned that ghrelin plays a major role in energy balance by increasing appetite and food uptake and decreasing energy wasting $[13,14,20$, 21]. Studies on ghrelin levels in CF patients are few and their results are not unanimous.

Cohen et al. in 2010 found that CF subjects with low BMI had lower levels of lymphocytic ghrelin receptor expression, while cases with normal BMI and also controls were the same in this regard [14]. In another study on adult CF cases, it was shown that the observed elevated ghrelin levels were a consequence of weight loss, not the cause of it [2].

Our results show that $\mathrm{BMI}$ and weight in $\mathrm{CF}$ patients are lower than the normal control group and the difference is statistically significant. Also the results show that the plasma levels of acylated ghrelin in CF patients are higher than in the normal control group, which is also statistically significant. These findings are in accordance with the data which support ghrelin's positive effect on increasing appetite and food intake, which lead to a positive energy balance [20-23].

Although there were significant differences between the two groups in BMI (weight and plasma ghrelin levels), there was no correlation between plasma ghrelin levels and BMI or weight. Our data showed decreased levels of plasma albumin in CF patients in comparison to the control group. This 
finding is in accordance with studies which show decreased plasma albumin in CF patients, which may be due to pancreas or gastrointestinal (GI) tract involvement, malnutrition or respiratory failure in these patients, but our patients had normal pancreas and GI tract function, established by the normal fecal fat test in them [24]. Also participants in this study were clinically stable and no acid-base disorder or pulmonary exacerbation was detected by the clinicians or found in their records. According to the increased level of acylated ghrelin in our results, it could be concluded that hypoalbuminemia observed in our patients may be due to malnutrition and energy balance deficiency. There are also case reports of undetermined hypoalbuminemia in CF patients with severe esophagitis without GI or pancreatic involvement. In the mentioned studies, hypoalbuminemia resolved after esophagitis was cured [25].

To our knowledge, no study has examined the relation between plasma level of acylated ghrelin with CF disease. The few existing studies explored unacylated ghrelin levels in CF patients; most of them showed increased levels of plasma ghrelin in CF patients, although some showed opposite results $[1,2]$.

In conclusion, acylated ghrelin levels are increased in CF patients, probably due to energy deficiency in them, and this shows that plasma ghrelin levels have an inverse relation to energy uptake. So plasma levels of acylated ghrelin could be used as an indicator of food uptake and energy balance in CF patients.

There were some limitations in our study. Lung performance was not measured in this study to analyze the relation between acylated ghrelin level and pulmonary function. Also tissue ghrelin levels should be measured to have a better interpretation of the body response to the disease. And as we know, CF is the result of a spectrum of mutations and the differences we noted may be due to the divergent nature of the disease. Further studies should be performed to determine the exact role of factors affecting energy metabolism and their relations and interactions with each other.

\section{Acknowledgments}

The authors thank Mrs. Heshmat Irani and Leila Kashi for their technical support. Financial support was provided by Tehran University of Medical Sciences.

\section{References}

1. Stylianou C, Galli-Tsinopoulou A, Koliakos G, et al. Ghrelin and leptin levels in young adults with cystic fibrosis: relationship with body fat. J Cyst Fibros 2007; 6: 293-6.

2. Cohen RI, Tsang D, Koenig S, Wilson D, McCloskey T, Chandra S. Plasma ghrelin and leptin in adult cystic fibrosis patients. J Cyst Fibros 2008; 7: 398-402.
3. Kojima M, Hosoda H, Date Y, Nakazato M, Matsuo H, Kangawa K. Ghrelin is a growth-hormone-releasing acylated peptide from stomach. Nature 1999; 402: 656-60.

4. Romero A, Kirchner H, Heppner K, Pfluger PT, Tschöp MH, Nogueiras R. GOAT: the master switch for the ghrelin system? Eur J Endocrinol 2010; 163: 1-8.

5. Staes E, Absil PA, Lins L, et al. Acylated and unacylated ghrelin binding to membranes and to ghrelin receptor: towards a better understanding of the underlying mechanisms. Biochim Biophys Acta 2010; 1798: 2102-13.

6. Barboza MA, Mattos CC, Barja PR, Oliveira LV, Mattos LC. Influence of secretor and non secretor phenotypes on the solubilization of pulmonary mucus by three common medicines in cystic fibrosis patients assessed using photoacoustic analysis. Arch Med Sci 2008; 4: 386-91.

7. Broglio F, Arvat E, Benso A, et al Ghrelin, a natural GH secretagogue produced by the stomach, induces hyperglycemia and reduces insulin secretion in humans. J Clin Endocrinol Metab 2001; 86: 5083-6.

8. van der Lely AJ, Tschöp M, Heiman ML, Ghigo E. Biological, physiological, pathophysiological, and pharmacological aspects of ghrelin. Endocr Rev 2004; 25: 26-57.

9. Leite-Moreira AF, Soares JB. Physiological, pathological and potential therapeutic roles of ghrelin. Drug Discov Today 2007; 12: 276-88.

10. Diano S, Farr SA, Benoit SC, et al. Ghrelin controls hippocampal spine synapse density and memory performance. Nat Neurosci 2006; 9: 381-8.

11. Kojima M, Kangawa K. Ghrelin structure and function. In: Civelli O, Zhou QY, editors. Orphan G Protein-coupled receptors and novel neuropeptides. Springer, Berlin 2008; 90-115.

12. Zhu X, Cao Y, Voogd K, Steiner DF. On the processing of proghrelin to ghrelin. J Biol Chem 2006; 281: 38867-70.

13. Yang J, Brown MS, Liang G, Grishin NV, Goldstein JL. Identification of the acyltransferase that octanoylates ghrelin, an appetite-stimulating peptide hormone. Cell 2008; 132: 387-96.

14. Cohen RI, Chandra S, Koenig S, Tsang D, Wilson D, MCCloskey T. Ghrelin receptor expression in lymphocytes isolated from adult cystic fibrosis patients. Respiration 2010; 79: 141-6.

15. Rzymski P, Skórzewska A, Skibińska-Zielińska M, Opala T. Factors influencing breast elasticity measured by the ultrasound shear wave elastography - preliminary results. Arch Med Sci 2011; 7: 127-33.

16. Moshtaghi-Kashanian GR, Razavi F. Ghrelin and leptin levels in relation to puberty and reproductive function in patients with beta-thalassemia. Hormones 2009; 8: 207-13.

17. Fine KD, Ogunji F. A new method of quantitative fecal fat microscopy and its correlation with chemically measured fecal fat output. Am J Clin Pathol 2000; 113: 528-34.

18. Wang L, Freedman SD. Laboratory tests for the diagnosis of cystic fibrosis. Am J Clin Pathol 2002; 117 (Suppl.): S109-15.

19. Fallahi G, Najafi M, Farhmand F, et al. The clinical and laboratory manifestations of Iranian patients with cystic fibrosis. Turk J Pediatr 2010; 52: 132-8.

20. Wren AM, Seal LJ, Cohen MA, et al. Ghrelin enhances appetite and increases food intake in humans. J Clin Endocrinol Metab 2001; 86: 5992.

21. Fry M, Ferguson AV. Ghrelin: central nervous system sites of action in regulation of energy balance. Int J Pept 2010; 2010: 616757.

22. Otto B, Cuntz U, Fruehauf E, et al. Weight gain decreases elevated plasma ghrelin concentrations of patients with anorexia nervosa. Eur J Endocrinol 2001; 145: 669-73. 
23. Schwandt SE, Peddu SC, Riley LG. Differential roles for octanoylated and decanoylated ghrelins in regulating appetite and metabolism. Int J Pept 2010; 2010: 275804.

24. Holland AE, Wilson JW, Kotsimbos TC, Naughton MT. Metabolic alkalosis contributes to acute hypercapnic respiratory failure in adult cystic fibrosis. Chest 2003; 124: 490-3.

25. Bozic MA, Howenstine MS, Maguiness KM, Molleston JP. Hypoalbuminemia in a cystic fibrosis patient with severe erosive esophagitis. Nutr Clin Pract 2010; 25: 304-7. 